\title{
High School Athletic Directors Report Poor Compliance With Concussion Reporting and Medical Clearance in Massachusetts
}

\author{
Joseph B. Kahan, M.D., M.P.H., Matthew Salzler, M.D., Danielle DiCenzo, B.A., \\ Thomas Zink, B.A., Zachary Radford, B.A., and David Tybor, M.P.H., Ph.D.
}

\begin{abstract}
Purpose: To assess statewide prevalence of medical access, concussion reporting, and concussion clearance rates of high school athletic departments in Massachusetts after the implementation of state-wide concussion legislation. Methods: A random sample of 50 athletic directors (ADs) from Massachusetts high schools with an enrollment of $>150$ students was selected. A 10-minute electronic survey about access to athletic trainers and physicians, and concussion reporting and clearance practices was administered. Responses were anonymous. Results: The response rate was $80 \%$ ( $\mathrm{n}=40$ ). In total, $90 \%$ of respondents were male. Median age and experience of respondents was 52 years old and 10 years, respectively. The median school size was 637 students, represented from all Massachusetts geographic athletic districts. ADs disclosed that on average, 12\% (95\% confidence interval 7\%-20\%) of concussions go unreported at their schools. In total, $16 \%$ of respondents reported that at least 1 in 4 of concussed athletes at their school returned to play without appropriate medical clearance, and $5 \%$ of ADs reported that not all of their coaches had undergone any form of concussion training. Overall, 55\% of high schools do not have access to a full-time athletic trainer and $50 \%$ do not have a team physician; $20 \%$ have affiliations with an orthopaedic surgeon and $8 \%$ with a neurologist. Conclusions: Despite new regulations in Massachusetts, high school ADs report concussion reporting and clearance that are less than $100 \%$. Less than one half of all Massachusetts high schools report access to a full-time athletic trainer or formal relationship with a school physician. Clinical Relevance: Investigating compliance with Massachusetts school athletics safety regulations could help identify a need for reform of policies designed to help schools keep student athletes safer in situations where a concussion may have occurred.
\end{abstract}

I

n 2006, 13-year-old Zachary Lystedt sustained permanent brain damage after returning to play in the same football game that he sustained a concussion. ${ }^{1}$ Since then, nearly every state has passed concussion legislation requiring standardized reporting and clearance practices for high school athletes. ${ }^{2}$

From the Department of Orthopaedics and Rehabilitation, Yale University, New Haven, Connecticut (J.B.K.); Tufts Medical Center, Department of Orthopaedic Surgery (M.S.); and Tufts University School of Medicine (M.S., D.D., T.Z., Z.R., D.T.), Boston, Massachusetts, U.S.A.

The authors report that they have no conflicts of interest in the authorship and publication of this article. Full ICMJE author disclosure forms are available for this article online, as supplementary material.

Received February 16, 2020; accepted July 1, 2020.

Address correspondence to Joseph Kahan, M.D., M.P.H., Department of Orthopaedic Surgery, Yale University, 47 College Ave., New Haven, CT 06511.E-mail: Jory.Kahan@gmail.com

(C) 2020 THE AUTHORS. Published by Elsevier Inc. on behalf of the Arthroscopy Association of North America. This is an open access article under the CC BY-NC-ND license (http://creativecommons.org/licenses/by-nc-nd/4.0/).

2666-061X/20216

https://doi.org/10.1016/j.asmr.2020.07.002
Diagnosing and managing concussions is challenging because they present with a wide range of clinical signs and symptoms ${ }^{3}$ and are often neither recognized by athletes nor observed by coaches or athletic trainers. ${ }^{2,4}$ Premature return to play can have permanent consequences, ${ }^{3,5,6}$ and even high school-aged athletes can develop chronic traumatic encephalopathy with repetitive injuries. ${ }^{7}$ Preventing inappropriate return to play while symptomatic is essential to prevent long-term concussion sequelae. Evidence suggests that a second impact while an athlete is incompletely recovered from a concussion carries the added risk of increased likelihood of fatal or highly morbid injuries, and that concussive effects may be prolonged when not removed immediately from play, adding further importance to proper clearance before return to play. ${ }^{6,8}$ From 2005 to 2015 , there were a total of 28 traumatic brain and spinal cord injury deaths in high school and college football: $18 \%$ were preceded by an earlier concussion.'

Despite these risks, many high school athletes do not report their injuries or do not understand the health 
Table 1. Athletic Director and High School Characteristics in Massachusetts, 2017 ( $\mathrm{n}=40$ )

\begin{tabular}{lccc}
\hline & $\%$ & Median & 25th, 75th Percentile \\
\hline Athletic director & & 52 & 45,61 \\
$\quad \begin{array}{l}\text { Age, y } \\
\text { Sex }\end{array} \quad$ & & \\
$\quad$ Male & $90 \%$ & & 6,17 \\
$\quad \begin{array}{l}\text { Experience, y } \\
\text { Number of head coaches }\end{array}$ & & 26 & 21,33 \\
School & & & \\
$\quad \begin{array}{l}\text { Number of students } \\
\text { Type }\end{array}$ & & 637 & 466,1084 \\
$\quad$ Public & & & \\
$\quad$ Private & $85 \%$ & & \\
\hline
\end{tabular}

consequences of premature return to play.,10 Many high school athletes continue to play with concussive symptoms. ${ }^{4,11,12}$ Only a minority seek medical help. ${ }^{11}$

High school athletes in particular have protracted recovery times compared with other populations, a situation exacerbated when coaches, athletic trainers, and other sports medicine professionals do not properly follow guidelines for concussion assessment and management. ${ }^{13}$ Such guidelines are highlighted by the American Academy of Neurology, which recommends that doctors who clear athletes for return to sports should be specifically trained in managing and accessing sports-related concussions. ${ }^{14}$

Since 2011, 44 states have enacted legislation focused on concussions in youth sports. ${ }^{15}$ In 2010 , Massachusetts passed An Act Relative to Safety Regulations for School Athletic Programs (2010 Mass Session Law Chapter 166, 19 July 2010), mandating that by 2011 , all coaches undergo concussion training, all concussions be reported to the state athletic conference, and all athletes who are concussed receive medical clearance before returning to play by a medical practitioner trained in concussion management. ${ }^{16}$ The law did not specifically describe how the mandates were to be carried out but rather delegated responsibility of oversight, including auditing and punishment for failure to comply, to the Massachusetts Department of Public Health Division of Violence and Injury Prevention. While the Massachusetts Department of Public Health has studied concussion incidence and removal from play via surveys of high school students, ${ }^{11}$ there is limited research regarding school injury reporting practices, rates of medical clearance before return to play, rates of concussion awareness training for high school coaches, or athlete access to medical professionals.

The purpose of this study was to assess statewide prevalence of medical access, concussion reporting, and concussion clearance rates of high school athletic departments in Massachusetts after the implementation of state-wide concussion legislation. We hypothesized that there would be imperfect compliance to the Massachusetts school athletics safety regulations, which, if true would imply a need for reform of policies designed to help schools comply with such regulations.

\section{Methods}

We acquired a list of all schools that participated in the Massachusetts Interscholastic Athletic Association in 2016 to 2017 from the Massachusetts Department of Education. All schools with a total enrollment greater than 150 students in grades 9 to 12 were included in the sampling frame. Stata, version 14 (StataCorp, College Station, TX) was used to select a random sample of 50 eligible high schools.

A 10-minute self-administered survey was developed and administered to a separate group of 10 high school athletic directors (ADs) before administration to the random sample. This survey included information about school access to athletic trainers and physicians, concussion training for coaches, injury and concussion reporting practices, and injury and concussion clearance practices. The survey asked ADs about practices at their own schools. The survey also asked athletic directors about their perception of practices at other schools statewide, in an effort to eliminate social desirability bias, which may lead ADs to under-report their own lack of compliance.

To maximize the survey response rate, a mixedmethods approach with e-mail and phone calls as described in prior other survey methods was used. ${ }^{17}$ Surveys were first sent electronically to all 50 ADs, and followed with phone calls explaining the purpose of the survey and providing opportunities to answer any clarifying questions. Surveys were collected during a 4-month response window during the 2016-2017

Table 2. High School Access to Trainers/Physicians, and Training History for Coaches, as Reported by Massachusetts High School Athletic Directors, 2017 ( $\mathrm{n}=40)$

\begin{tabular}{lrr}
\hline & Frequency & $\%$ \\
\hline School access to trainers & & \\
Good access & 2 & 5 \\
Multiple full-time trainers & 16 & 40 \\
$\quad$ Single full-time trainer & 11 & 28 \\
Poor access & 3 & 7 \\
Part-time trainer & 8 & 20 \\
Per-diem trainer & & \\
No access to trainers & 13 & 33 \\
Formal affiliation with physician & 8 & 20 \\
Yes & 3 & 8 \\
$\quad$ General pediatrician/primary care physician & 20 & 50 \\
$\quad$ Orthopaedic surgeon & & \\
$\quad$ Neurologist or neuro-psychiatrist & 7 & 18 \\
$\quad$ No & & \\
Coaches' training history & 2 & 5 \\
Not all coaches have received general safety or & & \\
$\quad$ first aid training & & \\
Not all coaches have received formal concussion & & \\
$\quad$ training & & \\
\hline & & \\
\hline
\end{tabular}




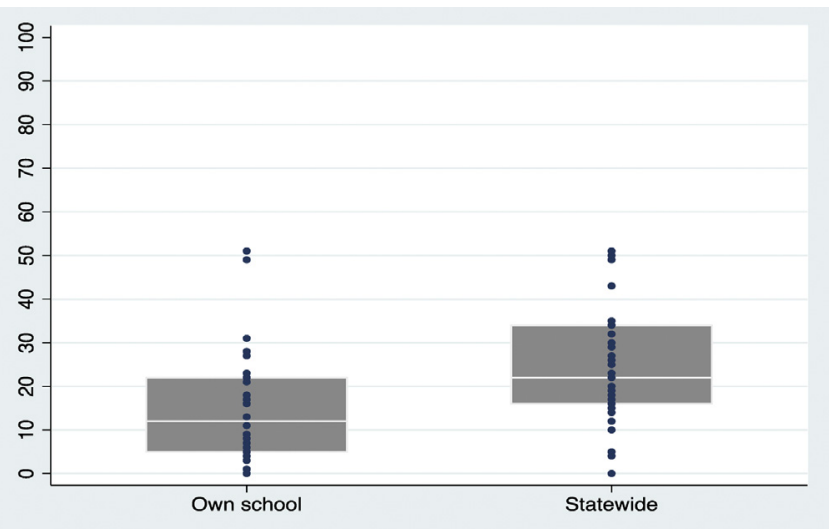

Fig 1. Massachusetts athletic director report of the percentage of concussions unreported in 2017, at their own school and statewide ( $\mathrm{n}=38$ : dots represent individual responses; boxes represent 25 th, 50 th, and 75 th percentiles).

high school academic year. The survey was administered electronically using SurveyMonkey, Inc. (San Mateo, CA). All responses were anonymous.

We calculated proportions, means, medians, and confidence intervals (CIs) as appropriate. The study was approved by the Tufts University institutional research board (exempt from institutional research board review under exemption 45 CFR 46.101(b) (2); no. 12290). We conducted all statistical analysis using Stata, version 14 (StataCorp) with a 2-sided alpha level of 0.05.

\section{Results}

The response rate for our survey was $80 \%$. Two respondents initiated the survey but did not finish. Respondent demographics are shown in Table 1. Almost all ADs were male $(90 \%)$. The median age of respondents was 52 (interquartile range [IQR] 45, 61). Their median experience as AD was 10 years (IQR 6, 17).

The median school had 637 students in grades 9-12. In Massachusetts, there are 8 geographic athletic districts, and each district had at least 2 respondents. Of our respondents, $85 \%$ worked for public schools and $15 \%$ for private schools.

More than one half of high schools (55\%) reported poor access to athletic trainers (Table 2). Similarly, 50\% of high schools did not have a formal affiliation with a physician. Only $20 \%$ of high schools reported affiliations with an orthopaedic surgeon and only $8 \%$ of high schools reported affiliations with a neurologist.

The median number of head coaches at the respondent schools was 26 (IQR 21, 33). In total, 18\% of ADs in Massachusetts reported that not all of their coaches had taken a first aid course (95\% CI 8.3\%-23.0\%). In total, $5 \%$ of ADs reported that not all of their coaches had undergone any form of concussion training $(95 \%$ CI $1 \%-17 \%$ ). Only 2 of the 40 ADs reported that all of their coaches underwent a formal, in-person concussion training course.
The median $\mathrm{AD}$ reported that $12 \%$ of concussions went unreported at their own schools $(95 \%$ CI $7 \%-20 \%$ ) and $16 \%$ of ADs reported that at least 1 of every 4 concussions went unreported (Fig 1). In regard to return-to-play clearance, the median $\mathrm{AD}$ reported that only $1 \%$ of concussed athletes return to play before appropriate medical clearance (95\% CI 0\%-1\%). However, there was considerable variability in response, as $13 \%(5 / 38)$ of ADs admitted that at least 1 of 4 athletes who were concussed returned to play before obtaining appropriate medical clearance at their own schools (Fig 2).

When asked about their perceptions of concussion reporting throughout the state, ADs estimated greater rates of unreported concussions and greater rates of return-to-play without proper medical clearance for all injuries and concussions specifically (Table 3). Of note, $16 \%$ of ADs believe that at least one half of concussions go unreported statewide, and $32 \%$ of ADs believed that at least 1 of every 4 athletes who were concussed in Massachusetts did not receive appropriate medical clearance before returning to play.

\section{Discussion}

Despite a 2011 Massachusetts legislation mandating training, reporting, and medical clearance for concussions, our study demonstrates that high school ADs believe concussion reporting and clearance are less than $100 \%$. In addition, less than one half of all Massachusetts high schools report access to a full-time athletic trainer or formal relationship with a school physician.

This 2011 Massachusetts legislation specifically mandates that all athletes who suffer a head injury during practice or competition must be removed from play and may not return until they have received medical clearance from an athletic trainer, nurse practitioner,

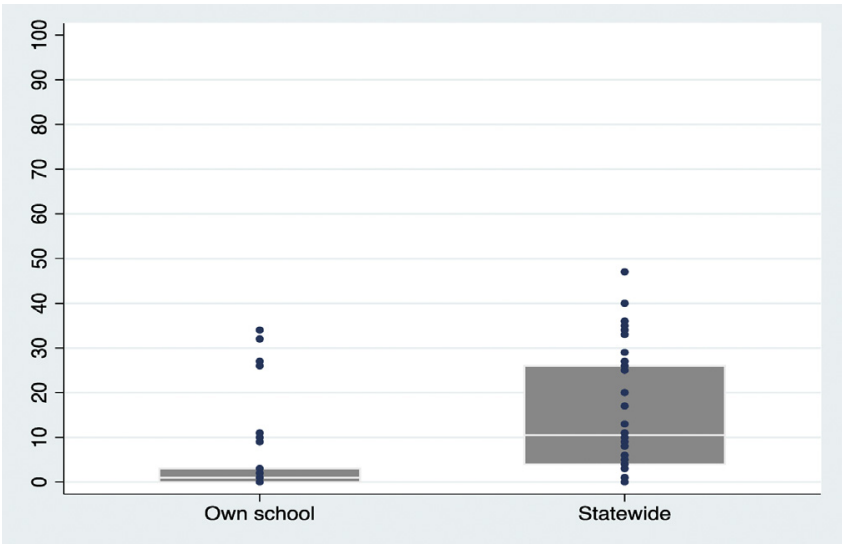

Fig 2. Massachusetts athletic director report of the percentage of concussed athletes returning to play before receiving appropriate medical clearance in 2017, at their own school and statewide $(\mathrm{n}=38$ : dots represent individual responses; boxes represent 25 th, 50th, and 75 th percentiles). 
Table 3. Athletic Director Report of Unreported Injuries, Unreported Concussions, and Insufficient Medical Clearance Postinjury, at Own School and Statewide ( $\mathrm{n}=38$, Massachusetts, 2017)

\begin{tabular}{|c|c|c|c|c|}
\hline & Median $(95 \% \mathrm{CI})$ & Min & Max & $\begin{array}{l}\text { 25th, } 75 \text { th } \\
\text { Percentiles }\end{array}$ \\
\hline \multicolumn{5}{|l|}{ Percent of concussions not reported } \\
\hline At athletic director's own school & $12(7-20)$ & 0 & 51 & 5,22 \\
\hline \multicolumn{5}{|c|}{$\begin{array}{l}\text { Percent of time medical clearance was not obtained before allowing athletes to return } \\
\text { to play after sustaining any type of injury }\end{array}$} \\
\hline At athletic director's own school & $1(0-4)$ & 0 & 49 & 0,6 \\
\hline At athletic director's own school & $1(0-1)$ & 0 & 34 & 0,3 \\
\hline Statewide & $11(7-20)$ & 0 & 47 & 4,26 \\
\hline
\end{tabular}

CI, confidence interval.

physician assistant, or physician. ${ }^{16,18}$ Further, coaches are required to report all head injuries to their $\mathrm{AD}$ and school nurse within 24 hours, and ADs are responsible for reporting annual statistics to the Department of Public Health. ${ }^{18}$ Our data suggest imperfect compliance for improvement in all realms, with ADs reporting that $12 \%$ of concussions go unreported at their schools. This may be due in part due to lack of awareness among coaches, as ADs also reported a lack of concussion training for all coaches.

Previous research has investigated the number of athletes who sought medical care after sustaining a concussion, ${ }^{11}$ but there is limited research regarding the percent who received medical clearance before returning to play. With random selection and a high response rate, we were able to estimate the number of athletes who were concussed statewide who did not receive medical clearance before returning to play.

In the 2016-2017 season, nearly 230,000 unique high school athletes participated in the Massachusetts Interscholastic Athletic Association. ${ }^{19}$ Using a cumulative incidence of $14 \%$ per season, as reported in a 2015 survey of Massachusetts public school students, ${ }^{11}$ we estimate that there were approximately 32,000 high school athletes who sustained a concussion within 20162017 academic year. Our research suggests that of those possible 32,000 concussed athletes, potentially 320 did not receive medical clearance before returning to play.

Our concussion reporting findings are consistent with 2013-2014 data from the Massachusetts Department of Public Health, showing that of the more than 700 schools required to submit concussion reporting data, more than 200 schools did not submit reports. An additional 142 schools reported no head injuries for the entire year. 8,19

The implications of continued play with concussive symptoms have been well documented, with secondimpact syndrome and repetitive prolonged concussive effects potentially causing highly morbid and even fatal events. $^{6,8}$ We suggest that opportunities exist to improve health care access and education in an effort to remedy the poor diagnosis, reporting, and management of high school concussions. We believe that access to care remains the most significant barrier to appropriate head injury evaluation and management. Our data demonstrated that the majority of high schools have poor access to athletic trainers and team physicians. More than one half of high school athletic departments lack formal relationships with physicians and do not have full-time athletic trainers. Improving access should be a main focus of future interventions.

\section{Limitations}

Our study has inherent limitations associated with a survey study. Our data rely on the self-report of ADs, who may, knowingly or unknowingly, incorrectly recall the concussion reporting and clearance data for their school. Social desirability bias suggests that they would likely overstate rates of clearance and reporting, given that anything less than $100 \%$ is not in compliance with the law. Therefore, our reported data are likely a "best-case" scenario, and the true practices are perhaps bleaker than reported here, as reflected by the higher statewide estimates based on AD perception

Another limitation of this study was lack of validation of the survey. Although attempts were made to increase face validity with an initial trial survey, appropriate survey validation remained a challenge. Because it is impossible to objectively measure the number of unreported concussions, there is no sample to with which to compare $\mathrm{AD}$ estimates to validate our survey.

We were unable to recruit all ADs in our sample, introducing potential response bias. However, if a school were adhering perfectly to the regulations, it is likely their ADs would be more motivated to respond, further suggesting that our data are overestimates of rates of clearance and reporting. Future research should investigate current practices in other states. Researchers 
should also examine which school-level factors are associated with better access, reporting and clearance.

Finally, we recognize that this study represents opinions and beliefs of ADs. It is impossible to quantify the exact number of concussions in the state of Massachusetts, and the number that are unreported or do not seek medical attention. However, we demonstrated that ADs are reporting difficulties complying to the Massachusetts head injury legislation. Further study is needed to understand where these difficulties lie, and how athletic departments and high schools can be better supported to address the healthcare needs of their athletes.

\section{Conclusions}

Despite new regulations in Massachusetts, high school ADs report concussion reporting and clearance that are less than $100 \%$. Less than one half of all Massachusetts high schools report access to a full-time athletic trainer or formal relationship with a school physician.

\section{References}

1. Adler RH. Youth sports and concussions: Preventing preventable brain injuries. One client, one cause, and a new law. Phys Med Rehabil Clin N Am 2011;22:721-728. ix.

2. Tomei KL, Doe C, Prestigiacomo CJ, Gandhi CD. Comparative analysis of state-level concussion legislation and review of current practices in concussion. Neurosurg Focus 2012;33:1-9 (E11).

3. Meehan WP 3rd, d'Hemecourt P, Comstock RD. High school concussions in the 2008-2009 academic year: Mechanism, symptoms, and management. Am J Sports Med 2010;38(12):2405-2409.

4. Daneshvar DH, Nowinski CJ, McKee AC, Cantu RC. The epidemiology of sport-related concussion. Clin Sports Med 2011;30:1-17. vii.

5. McKee AC, Alosco ML, Huber BR. Repetitive head impacts and chronic traumatic encephalopathy. Neurosurg Clin N Am 2016;27:529-535.

6. Quintana LM. Second impact syndrome in sports. World Neurosurg 2016;91:647-649.
7. Mez J, Daneshvar DH, Kiernan PT, et al. Clinicopathological evaluation of chronic traumatic encephalopathy in players of American football. JAMA 2017;318:360-370.

8. Cantu RC. Recurrent athletic head injury: Risks and when to retire. Clin Sports Med 2003;22:593-603. x.

9. Kucera KL, Yau RK, Register-Mihalik J, et al. Traumatic brain and spinal cord fatalities among high school and college football players-United States, 2005-2014. MMWR Morb Mortal Wkly Rep 2017;65:1465-1469.

10. Cusimano MD. Canadian minor hockey participants' knowledge about concussion. Can J Neurol Sci 2009;36: 315-320.

11. Massachusetts Risk Behavior Survey and Massachusetts Youth Health Survey. Health and Risk Behaviors of Massachusetts Youth Executive Summary. Department of Public Health. 017 Report. http://www.doe.mass.edu/sfs/ yrbs/2017exec-summary.pdf. Accessed June 1, 2018.

12. Zynda AJ, Sabatino MJ, Ellis HB, Miller SM. Continued play following sport-related concussion in United States youth soccer. Int J Exerc Sci 2020;13:87-100.

13. Covassin T, Elbin R 3rd, Stiller-Ostrowski JL. Current sport-related concussion teaching and clinical practices of sports medicine professionals. J Athl Train 2009;44: 400-404.

14. Gomez JE, Hergenroeder AC. New guidelines for management of concussion in sport: Special concern for youth. J Adolesc Health 2013;53:311-313.

15. Harvey HH. Reducing traumatic brain injuries in youth sports: Youth sports traumatic brain injury state laws, January 2009-December 2012. Am J Public Health 2013;103:1249-1254.

16. Doucette ML, Bulzacchelli MT, Gillum TL, Whitehill JM. The Massachusetts School Sports Concussions Law: A qualitative study of local implementation experiences. J Law Med Ethics 2016;44:503-513.

17. Smith JD, Christian LM, Dillman DA. Internet, phone, mail, and mixed-mode surveys. New York: John Wiley \& Sons, 2014.

18. Massachusetts Department of Public Health. Statewide sports concussion initiative: MA law and Department of Public Health regulations. https://malegislature.gov/Laws/ SessionLaws/Acts/2010/Chapter166. Accessed June 25, 2020. Published 2019.

19. Massachusetts Interscholastic Athletic Association. Massachusetts High School Athletes Participation. http:// www.miaa.net. Accessed June 1, 2017. Published 2017. 